\title{
Complete endoscopic management of tubular esophageal duplication in a young woman
}

A 29-year-old woman was referred to our department for endoscopic dilation of upper esophageal stricture. Dilation was performed with Savary-Gilliard dilators allowing the passage with resistance of a standard flexible video gastroscope (EG-201FP; Fujinon, Willich, Germany). Esophagogastroduodenoscopy showed a double esophageal lumen at $18 \mathrm{~cm}$ from the incisors. A thick bridge of intact mucosa separated the two lumens ( $\mathbf{F i g} \mathbf{1}$ ). The passage of the endoscope through the second lumen was not possible. At 32 $\mathrm{cm}$, a distal defect was also found. A barium esophagogram and high-resolution computed tomography (CT) scan confirmed esophageal tubular duplication (๑ Fig. 2 and $\bullet$ Fig.3).

Under general anesthesia, the standard video gastroscope was pushed down to the proximal opening of the duplication. After an easy passage of a 0.035-inch guide wire (Boston Scientific, Natick, MA, USA) in the duplicated lumen, a lengthwise incision of the intraluminal bridge was performed by using a 5.5-Fr needleknife (microKnife XL; Boston Scientific). The incision was performed step by step, from the upper to the distal end ( Fig.4, - Videos 1-3). The procedure was completed with dilation of the upper esophageal stricture by using a wire-guided balloon (Boston Scientific) advanced through the endoscope and expanded up to $12 \mathrm{~mm}$.

Biopsies performed along the incision showed the presence of malpighian epithelium. The patient's early post-procedural course was marked by an iatrogenic mediastinal emphysema and bilateral pneumothorax, more pronounced in the left. The placement of a left chest drain led to rapid improvement. Upper endoscopy on day 20 showed two longitudinal residual folds ( $\bullet$ Fig.5).

Endoscopic management of esophageal duplication was reported twice previously for the cystic form $[1,2]$. To our knowledge, only one case of endoscopic management of a tubular esophageal duplication has previously been reported [3]. Nevertheless, the procedure was decided upon after surgical examination through a right thoracoscopy. Our case highlights the possibility of complete endoscopic management of tubular esophageal duplication. The post-procedure pneumothorax could have been avoided by carbon dioxide insufflation [4].

\section{Endoscopy_UCTN_Code_TTT_1AO_2AN}

\section{Competing interests: None}
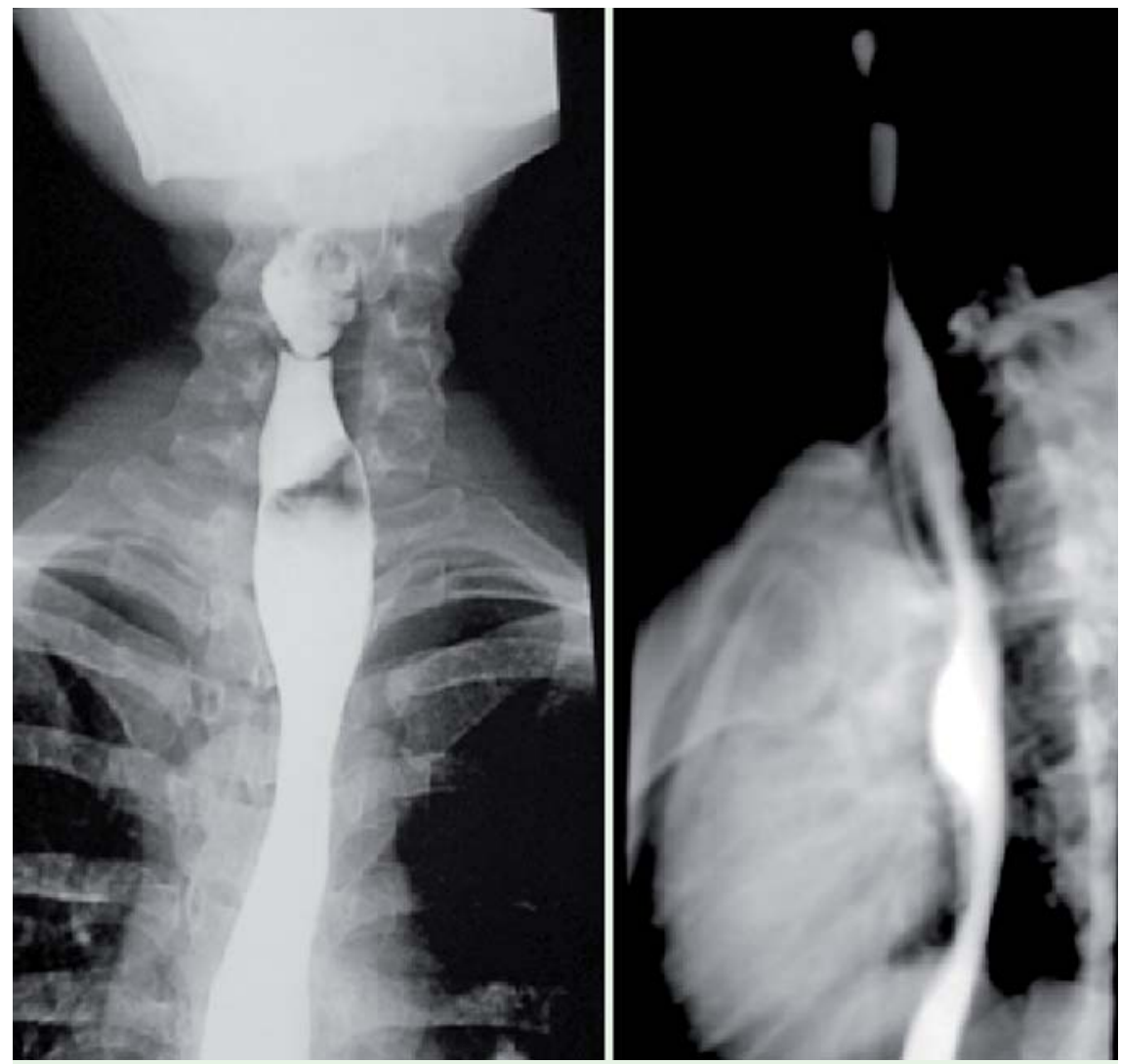

Fig. 2 Contrast study showing tubular duplication of the esophagus.

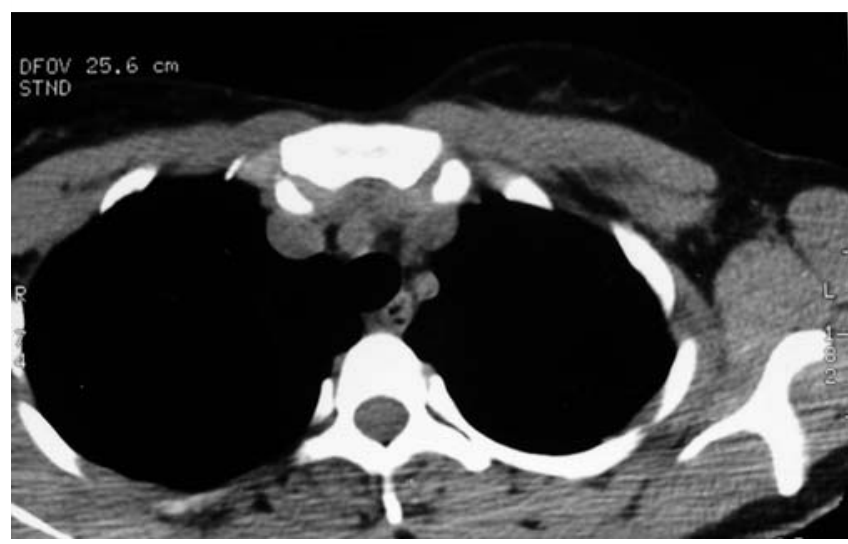

Fig. 3 Computed tomography (CT) scan showing evidence of tubular duplication of the esophagus. 


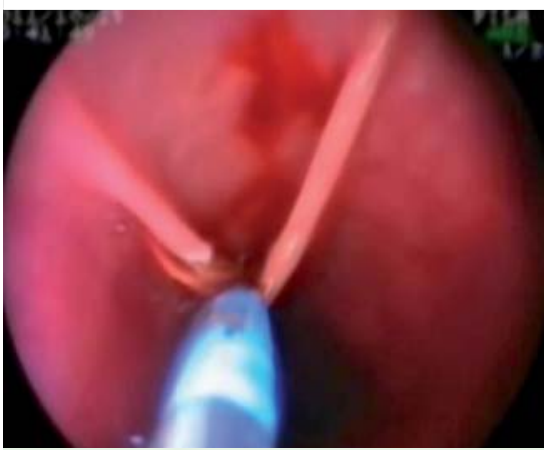

Fig.4 Image of interventional endoscopy showing incision of the intraluminal bridge by using a needle knife.

\section{Videos 1-3}

Interventional endoscopy: a lengthwise incision was made of the intraluminal bridge by using a needle knife starting from the upper end and achieved step by step. The procedure was completed with dilation of the upper esophageal stricture.

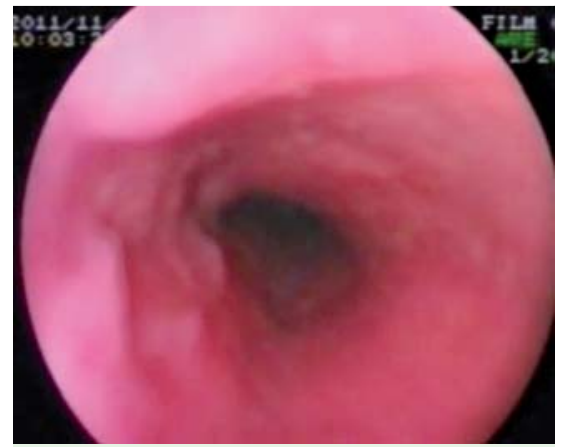

Fig. 5 Endoscopic image of two residual folds of the duplication.

N. Tahri ${ }^{1}$, L. Mnif ${ }^{1}$, L. Chtourou ${ }^{1}$,

M. Boudabbous ${ }^{1}$, K. Yaïch ${ }^{1}$, H. Fourati ${ }^{2}$, Z. Mnif ${ }^{2}$, A. Amouri

${ }^{1}$ Department of Gastroenterology, Hedi Chaker University Hospital, Sfax, Tunisia

2 Department of Radiology, Hedi Chaker University Hospital, Sfax, Tunisia

\section{References}

1 Will U, Meyer F, Bosseckert $H$. Successful endoscopic treatment of an esophageal duplication cyst. Scand J Gastroenterol 2005; 40: 995 - 999

2 Joyce AM, Zhang PJ, Kochman ML. Complete endoscopic resection of an esophageal duplication cyst (with video). Gastrointest Endosc 2006; 64: 288-289

3 Coumaros $D$, Schneider $A$, Tsesmeli $N$ et al. Endoscopic management of a tubular esophageal duplication diagnosed in adolescence (with video). Gastrointest Endosc 2010; 71: 827-830

4 Uemura $M$, Ishii $N$, Itoh $T$ et al. Effects of carbon dioxide insufflation in esophageal endoscopic submucosal dissection. Hepatogastroenterology 2011; 14: 115 - 116

\section{Bibliography}

DOI http://dx.doi.org/

10.1055/s-0032-1309705

Endoscopy 2012; 44: E261-E262

(c) Georg Thieme Verlag KG

Stuttgart · New York

ISSN 0013-726X

\section{Corresponding author}

\section{Mnif}

Department of Gastroenterology Hedi Chaker University Hospital

Route el Ain

3029 Sfax

Tunisia

Fax: +216-74-243993

leilamnif@yahoo.fr 